Brit. J. industr. Med., 1963, 20, 248.

\title{
THE COLLECTION OF EXPIRED VOLATILE SUBSTANCES
}

\author{
BY \\ J. C. GAGE \\ From Imperial Chemical Industries Ltd., Industrial Hygiene Research Laboratories, \\ The Frythe, Welwyn, Herts
}

(RECEIVED FOR PUBLICATION NOVEMBER 27, 1962)

\begin{abstract}
An apparatus is described in which the air exhaled by experimental animals is continuously extracted, permitting the collection of successive samples for the determination of volatile substances excreted by this route. Carbon dioxide output may be determined simultaneously by using a second extractor. The efficiency of the method has been checked with known concentrations of trichloroethylene and carbon dioxide in air.
\end{abstract}

In connexion with kinetic studies on the excretion of volatile substances through the lungs by small experimental animals, a method for the analysis of successive samples of expired air over a 24-hour period was required. In the course of these experiments it was realized that a simultaneous record of the carbon dioxide output would be of interest, as this might provide a correction for the varying respiratory rates of different animals, and of the same animal at different times.

\section{Description of the Apparatus}

The apparatus is shown diagrammatically in the Figure. The animal was housed in a modification of a unit previously described (Gage, 1961), constructed from a glass funnel sealed to a glass urine separator. The funnel was closed with a "perspex" lid provided with an air-tight rubber gasket, and a container for moist powdered diet and a water bottle were connected through the lid by a standard taper joint. A metered air-stream entered at the top of the urine separator and left through an exit tube in the lid.

The air from the animal container passed to the base of a cylindrical glass scrubber, $3 \mathrm{~cm}$. in diameter and $30 \mathrm{~cm}$. high, packed with stainless steel gauze rings. The extracting liquid trickled down the scrubber from a raised reservoir, the rate being controlled by the head of liquid and a suitable glass capillary. The constant level tube in the reservoir was connected to the top of the scrubber to overcome airpressure differences. The liquid from the scrubber collected at the narrow base and passed directly through a flexible polyvinyl chloride tube to a fraction collector; the height of this exit tube was adjusted so that a liquid seal was formed to prevent air leaving the scrubber at this point.

The air from the top of the scrubber passed to the base of an exactly similar unit. Both scrubbers delivered into diametrically opposite positions on the same fraction collector*, which was operated by an interval timer.

\section{The Efficiency of Extraction}

The efficiency of the extraction of trichloroethylene from air was checked using toluene as the extracting liquid. A trichloroethylene atmosphere containing $720 \mathrm{mg} . / \mathrm{m}^{3}$ was prepared as previously described (Gage, 1959) and passed through a scrubber down which trickled toluene at varying rates. The toluene was collected at 15 -minute intervals and a portion of each fraction was diluted with pyridine and analysed for trichloroethylene (Strafford, Strouts and Stubbings, 1956). The results are given in the Table.

For the preparation of a known carbon dioxide atmosphere, a molar solution of sodium carbonate was injected at a known rate into a flask containing an excess of $2 \mathrm{~N}$ sulphuric acid and through which bubbled carbon dioxide-free air at a rate of 0.5 1./min. The rate of injection was adjusted to give a

\footnotetext{
*Central Ignition Company Ltd.
} 


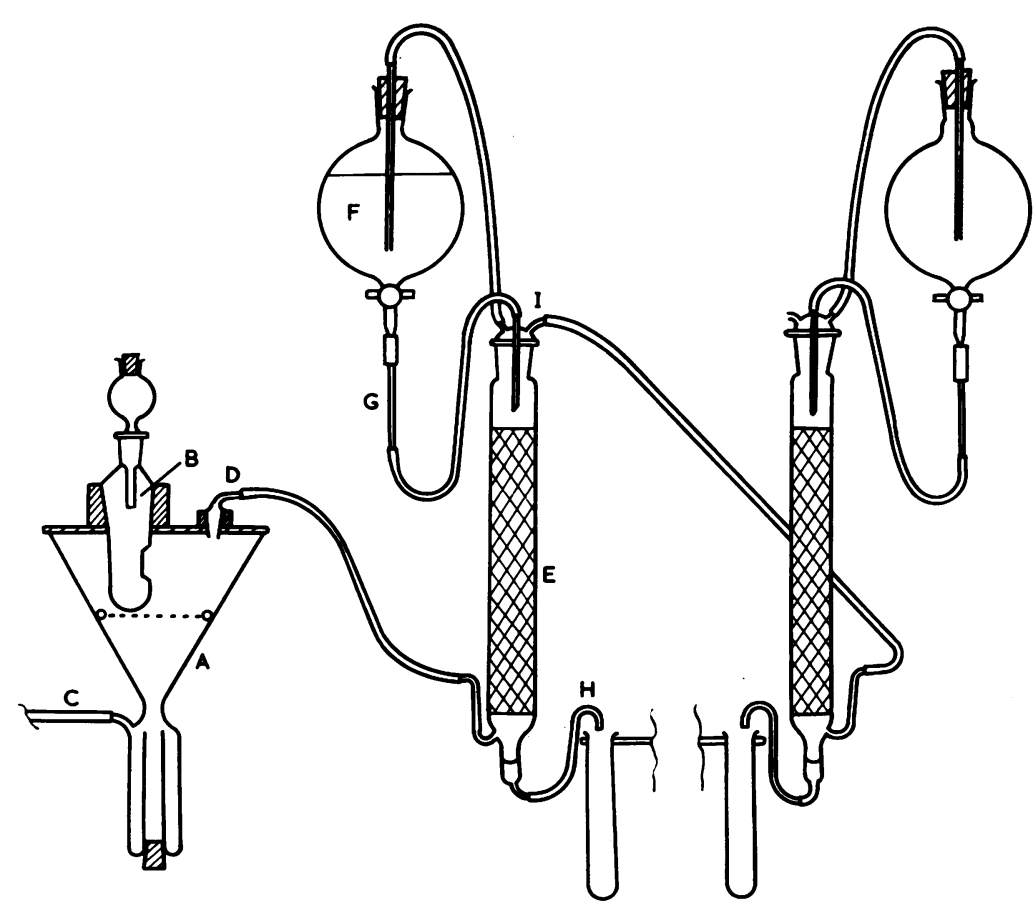

FIGURE. - Apparatus for the simultaneous collection of exhaled trichloroethylene and carbon dioxide. $A$, animal container; $B$, food and water supply; C, air line; D, exit tube; $E$, column of stainless stee gauze rings; $F$, liquid reservoir; $G$, capillary tube; $H$, liquid exit to fraction collector; I, air exit to second scrubber.

TABLE

THE EXTRACTION OF TRICHLOROETHYLENE AND CARBON DIOXIDE FROM AIR

\begin{tabular}{|c|c|c|c|c|c|}
\hline & \multirow{2}{*}{$\begin{array}{c}\text { Air Flow } \\
(1 . / \text { min. })\end{array}$} & \multirow{2}{*}{$\begin{array}{l}\text { Liquid Flow } \\
\text { (ml./hr.) }\end{array}$} & \multirow{2}{*}{$\underset{(\text { min.) }}{\text { Sampling Period }}$} & \multicolumn{2}{|c|}{ Collected in Successive Sampling Periods } \\
\hline & & & & $\overline{\text { Expected (mg.) }}$ & Found (mg.) \\
\hline Trichloroethylene $\left(720 \mathrm{mg} . / \mathrm{m}^{3}\right)$ & $\begin{array}{l}0 \cdot 5 \\
0 \cdot 5 \\
0 \cdot 5 \\
2 \cdot 0\end{array}$ & $\begin{array}{r}8 \\
20 \\
48 \\
20\end{array}$ & $\begin{array}{l}15 \\
15 \\
15 \\
15\end{array}$ & $\begin{array}{r}5 \cdot 6 \\
5 \cdot 6 \\
5 \cdot 6 \\
22 \cdot 4\end{array}$ & $\begin{array}{l}5 \cdot 25,5 \cdot 25,5 \cdot 45,5 \cdot 25 \\
5 \cdot 30,5 \cdot 46,5 \cdot 76,5 \cdot 56 \\
5 \cdot 70,5 \cdot 95,5 \cdot 55,5 \cdot 38 \\
22 \cdot 50,22 \cdot 25,20 \cdot 00,21 \cdot 00\end{array}$ \\
\hline Carbon dioxide $\left(12.4 \mathrm{~g} . / \mathrm{m}^{3}\right)$ & 0.5 & 60 & 20 & 124 & $125,122,123,123$ \\
\hline
\end{tabular}

carbon dioxide output of $6.2 \mathrm{mg}$./min. The reservoir contained $\mathrm{N}$ sodium hydroxide solution which was allowed to pass down the scrubber at a rate of 60 $\mathrm{ml} . / \mathrm{hr}$. It was found necessary carefully to free the rings from grease, as otherwise there was a tendency for the liquid to channel down the column, leading to a low extraction. Fractions were collected at 20 minute intervals and analysed for carbonate by titration. The error due to the absorption of atmospheric carbon dioxide by the fractions was overcome by placing a few millilitres of xylene in each tube of the collector at the beginning of the experiment. The results of such an experiment are given in the Table.

The results in the Table show that within 15 to 20 minutes the column has reached a steady state and that both trichloroethylene and carbon dioxide can be efficiently removed from an air-stream by this method. Experiments have also shown that with smaller air-flows the flow of the liquid down the column can be decreased without loss of efficiency. When both substances are being determined simultaneously no loss of carbon dioxide occurs when the air is passed first through the toluene scrubber.

The method of controlling the liquid flow down the column is adequate if the ambient temperature is constant. A simpler and somewhat more reliable means of achieving this flow is a continuous pump such as the Micro Pump Type $\mathbf{S}^{*}$.

\section{REFERENCES}

Gage, J. C. (1959). Brit. J. industr. Med., 16, 11

Stragi). (1bid., 18, 287 .

Strafford, N., Strouts, C. R. N., and Stubbings, W. V. (1956). The Determination of Toxic Substances in Air. A Manual of I.C.I. Practice. Heffer, Cambridge.

*Distillers Co., Ltd. 